\title{
Tongue involvement in Parry-Romberg syndrome with unilateral morphea
}

\section{Unilateral morfea eşliğinde Parry Romberg sendromu olgusunda dil tutulumu}

\author{
Leyla Baykal Selcuk ${ }^{1}$, Savas Yayli ${ }^{1}$ \\ ${ }^{1}$ Department of Dermatology, Karadeniz Technical University Faculty of Medicine, Trabzon, Turkey
}

Dear editor,

Parry-Romberg syndrome (PRS) is a very rare disorder which was initially described by Caleb Hilier Parry in 1825 and later by Moritiz Heinrich Romberg in 1846. ${ }^{1,2}$ It is characterized by progressive hemiatrophy of the skin, soft tissue, and deeper structures, such as musculature, cartilage, and osseous structures of the face. It may later progress to involve CNS system. Intraoral involvement may also occur with hemiatrophy of the tongue, teeth and mandible. ${ }^{3}$

A 15-year old female presented with some progressive changes at the left side of her face, including jaw-line, forehead and the tongue. She also complain some cutaneous atrophies at the same side of her body. At the first sight, an asymmetry was easily seen on at her face. A dermatologic examination revealed a mild linear depression at the forehead, and an atrophy at the left jawline (Fig. 1). Oral examination showed a hemiatrophy of tongue at the left-side with a loss of papillae (Fig. 2). At left-side of her back and her abdomen, she had many atrophic patches compatible morphea (Fig. 3). A potassium hydroxide preparation from her tongue was negative for candidiasis. Tests for anti-nuclear antibodies, and Borrelia burgdorferi were negative. At the neurology consultation, no significant clinical and MRI findings of brain were detected. However, at the MRI imaging of maxillofacial structures, hemiatrophy of left-side of her tongue was reported. The ipsilateral side of mandible was minimally affected. Frontal bones were normal. Treatment with oral prednisone with a dose of $0.5 \mathrm{mg} / \mathrm{kg} / \mathrm{d}$, and oral methotrexate $15 \mathrm{mg}$ week-

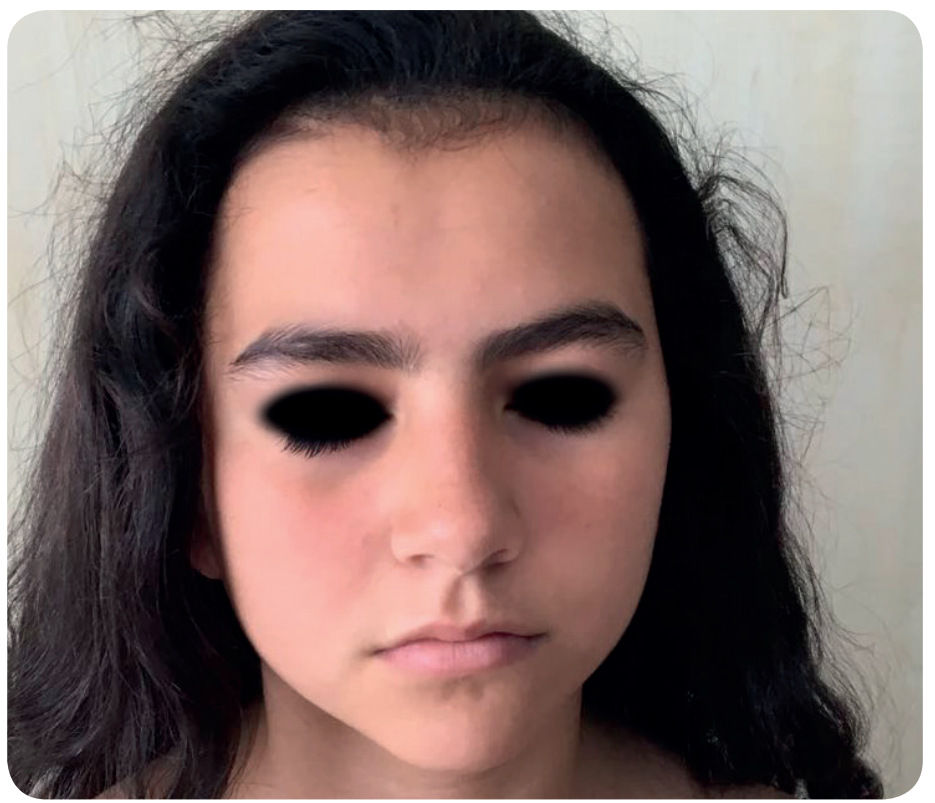

Fig. 1. A mild linear depression at the forehead, and an atrophy at the left jaw-line.

ly started. After three months, prednisone was stopped by gradually tapering the dose, methotrexate was continued nine months more. Skin lesions on her body had marked improvement, there were no progression of the lesions on her face and tongue. She is still in follow-up.

The involvement of half-face in our patient was characterized by both sclerotic and atrophic features. Coexistence of these clinical findings on her face, tongue and classic mor-

Corresponding author: Leyla Baykal Selcuk, Department of Dermatology, Karadeniz Technical University Faculty of Medicine, Trabzon, Turkey. Phone: +90 46237756 21, Fax: +90 46237751 56, E-mail: lb_leyla@hotmail.com

Received: 17 June 2018 Accepted: 22 June 2018

Conflicts of Interest: None 


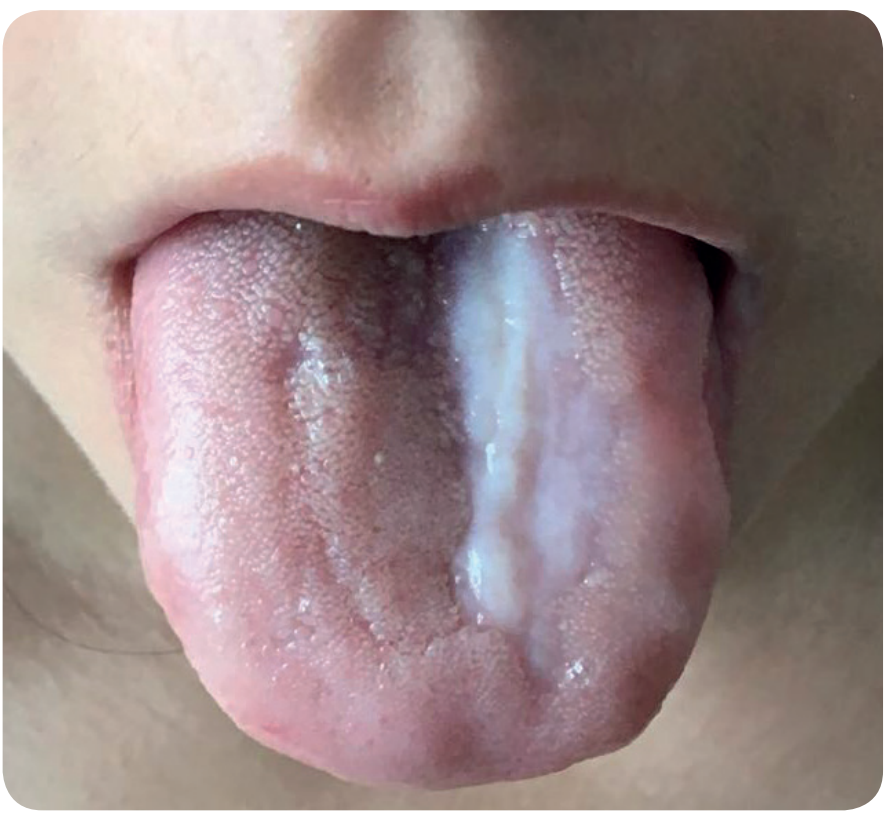

Fig. 2. Hemiatrophy of tongue at the left-side with a loss of papillae.

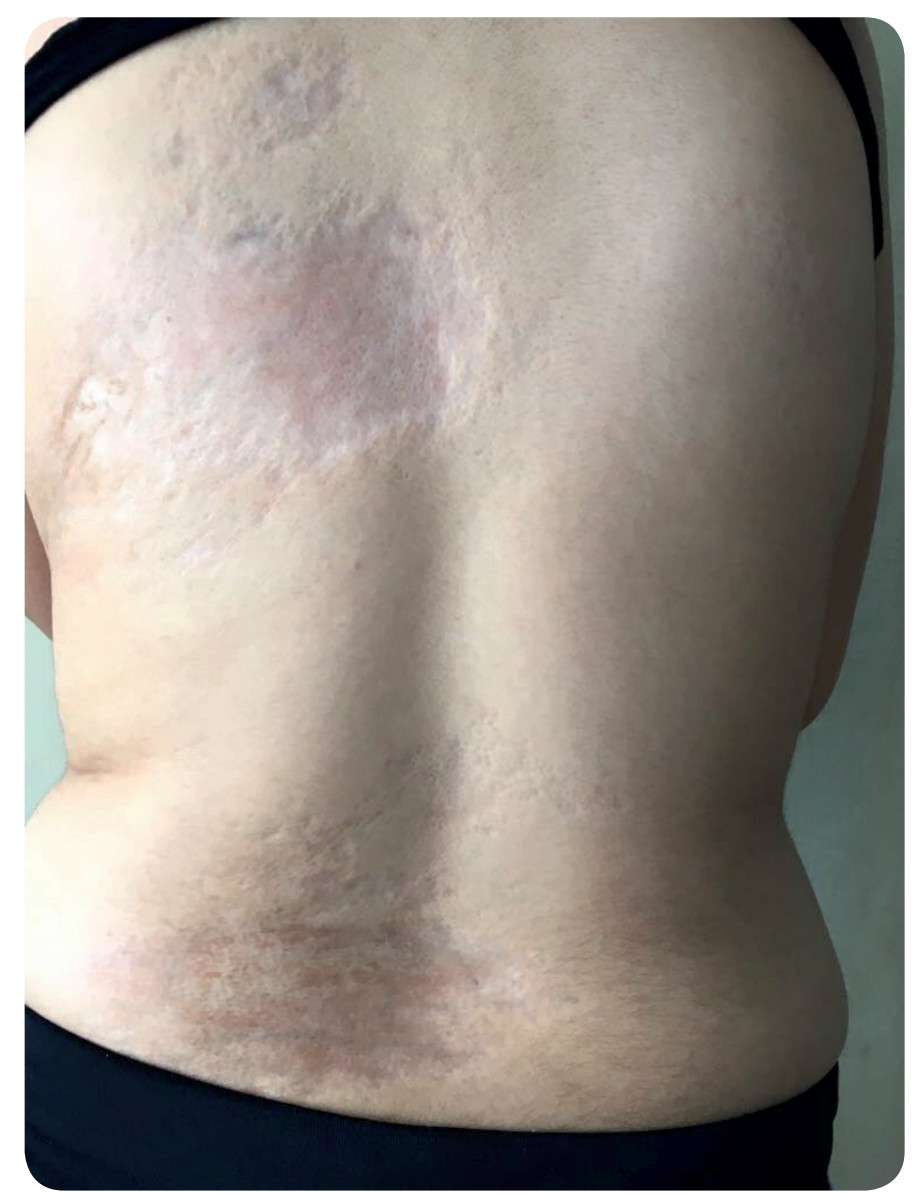

Fig. 3. Atrophic patches clinically compatible with morphea, at left-side of her back. phea lesions was rarely reported in the literature. ${ }^{4}$ The more reported association is the coexistence of linear scleroderma and progressive facial hemiatrophy. ${ }^{5}$ These two entities are very closely related forms of cranial and facial scleroderma with neurological manifestations. Indeed, in our case, on forehead, the clinical picture was also consistent with mild linear scleroderma, en coup de sabre. However, in our opinion, more striking features were the additional hemiatrophy of the tongue and unilateral morphea lesions on the trunk.

\section{References}

1. Parry CH. In: Collections from the unpublished medical writings of the late Caleb Hillies Parry, London, Underwoods, 1825;478.

2. Romberg HM. In:Klinische Ergebnisse, Berlin, Forrtner, 1846;75-81.

3. Sommer Al, Gambichler T, Bacharach-Buhles M, von Rothenburg T, Altmeyer P, Kreuter A. Clinical and serological characteristics of progressive facial hemiatrophy: a case series of 12 patients. J Am Acad Dermatol 2006;54:227-33.

4. Menni S, Marzano AV, Passoni E. Neurologic abnormalities in two patients with facial hemiatrophy and sclerosis coexisting with morphea. Pediatr Dermatol 1997;14:113-6.

5. Maletic J, Tsirka V, Ioannides P, Karacostas D, Taskos N. Parry-Romberg Syndrome Associated with Localized Scleroderma. Case Rep Neurol 2010;2:57-62. 